\title{
Radiation therapy at the end of life: a population-based study examining palliative treatment intensity
}

Marie-Adele Sorel Kress ${ }^{{ }^{*}}$, Roxanne E Jensen ${ }^{2}$, Huei-Ting Tsai ${ }^{2}$, Tania Lobo ${ }^{2}$, Andrew Satinsky ${ }^{1}$ and Arnold L Potosky ${ }^{2}$

\begin{abstract}
Background: To examine factors associated with the use of radiation therapy (RT) at the end of life in patients with breast, prostate, or colorectal cancer.

Methods: Using data from the Surveillance, Epidemiology, and End Results (SEER) - Medicare database, patients were over age 65 and diagnosed between January 1, 2004 and December 31, 2011 with any stage of cancer when the cause of death, as defined by SEER, was cancer; or with stage 4 cancer, who died of any cause. We employed multiple logistic regression models to identify patient and health systems factors associated with palliative radiation use.

Results: $50 \%$ of patients received RT in the last 6 months of life. RT was used less frequently in older patients and in non-Hispanic white patients. Similar patterns were observed in the last 14 days of life. Chemotherapy use in the last 6 months of life was strongly correlated with receiving RT in the last 6 months (OR 2.72, 95\% Cl: 2.59-2.88) and last 14 days of life (OR 1.55, 95\% Cl: 1.40-1.66). Patients receiving RT accrued more emergency department visits, radiographic exams and physician visits (all comparisons $\mathrm{p}<0.0001$ ).

Conclusions: Among patients with breast, colorectal, and prostate cancer, palliative RT use was common. End-of-life RT correlated with end-of-life chemotherapy use, including in the last 14 days of life, when treatment may cause increased treatment burden without improved quality of life. Research is needed optimize the role and timing of RT in palliative care.
\end{abstract}

Keywords: Palliative care, SEER-Medicare, Radiation therapy, Radiotherapy, Radiation oncology, End-of-life care

\section{Background}

In the last six months of life, cancer patients may undergo aggressive, costly care that often does not change their disease course, quality of life, or life expectancy $[1,2]$. Patients with breast, prostate and colorectal cancer often experience prolonged survival with metastatic or incurable disease, allowing time for a gradual shift in the focus of their medical care [3,4]. During this time, the goals of care can shift from cancer-directed treatment to comfort-directed care, addressing symptoms, physical function, and psychosocial health $[5,6]$.

\footnotetext{
* Correspondence: Marieadele.kress@gmail.com

'Huron River Radiation Oncology, 5301 E Huron River Dr Ann Arbor, Michigan 48106, USA

Full list of author information is available at the end of the article
}

Treatment in this time period must achieve the dual aims of improving or sustaining quality of life, while minimizing treatment time and burden. Radiation therapy (RT) is commonly used to palliate symptoms of metastatic cancer or prevent impending severe morbidity, and single-fraction RT can be more cost effective than alternative methods of pain relief, including pain medication or chemotherapy [7-9]. However, RT requires daily treatment that can also cause limited shortterm side effects, and it can require weeks after initiation of treatment to realize optimal palliation $[10,11]$. As a result, the timeliness of the use of RT is critical at the end of life: it needs to occur early enough to have meaningful clinical impact, and it may be inappropriate at the 
immediate-end of life due to high cost and burden of treatment time.

The American Society of Clinical Oncology (ASCO) added the use of chemotherapy in the last fourteen days of life as one of its Quality Oncology Practice Initiative (QOPI) measures, demonstrating the importance of limiting treatment burden toward the end of life $[12,13]$. Similarly, the American Society for Radiation Oncology (ASTRO) has released a guideline statement regarding the treatment of patients with bone metastases, a common site for treatment at the end of life [14]. However, no current RT guidelines exist regarding an appropriate paradigm for decision-making with respect to the utilization of RT at the end of life. Studies have demonstrated dependence of palliative RT use on multiple clinical and non-clinical factors [15-18]. However, these studies did not address the use of RT in the setting of patients with recurrent or progressive disease, nor did they specifically address treatment practices at the end of life, or the relationship between use of RT and other cancerdirected therapies, such as chemotherapy or surgery.

In this study, we address these issues in our examination of utilization of end-of-life RT among a population-based cohort of patients with breast, prostate, or colorectal cancer six months prior to death. We evaluated sociodemographic, clinical, health care environmental, and quality indicators associated with the use of RT during this time period. In particular, this study aimed to examine possible indicators of quality, such as treatment in the last 14 days of life.

\section{Methods}

\section{Data source and study cohort definition}

This study used data from the Surveillance, Epidemiology, and End Results (SEER) - Medicare linked database, which links persons in the SEER database with their clinical Medicare claims files. The SEER database is a database supported by the National Cancer Institute that includes information on patients diagnosed with cancer, about whom data was collected in 17 geographic areas covering $25 \%$ of the U.S. population [19]. The Medicare claims files include diagnostic and procedure codes for linked patients, and the linked database also provides sociodemographic information regarding persons in the database.

We identified 614,214 patients diagnosed with prostate, breast, or colorectal cancer between January 1, 2004 and December 31, 2011 (Figure 1). Prostate, breast, and colorectal cancer were chosen for their high relative incidence and due to patients' similar potential prolonged life with metastatic or advanced disease. With this group of three malignancies, the disease course and its subsequent treatment was more likely to have similar aims in the palliative setting. We investigated a cohort who either died with stage 4 cancer or died with cancer as the confirmed cause of death despite initial diagnosis of stage $0-3$ disease between 2004 and 2011. Patients were included if they were diagnosed at age 65 or older $(n=454,633)$, were not treated in a Health Maintenance Organization and were continuously eligible for Part A and B Medicare $(\mathrm{n}=$ 283,909), and who died on or before December 31, 2011 $(n=103,315)$. Subjects were included if they died between January 1, 2004 and December 31, 2011 of any stage of cancer when the cause of death, as defined by SEER, was cancer; or who were initially diagnosed with stage 4 cancer and died of any cause during this time period $(n=58,726)$, and for whom the diagnosed cancer was the subject's only malignancy or their first of no more than two malignancies $(n=42,141)$. We excluded subjects whom we suspected of errors in data linkage, or who had dual coverage (e.g., used VA services). Thus, we excluded cases who had only denied claims $(n=42)$, who had claims after death $(\mathrm{n}=120)$, who had no claims after date of diagnosis $(n=795)$, who did not have any claims in the last six months before death $(\mathrm{n}=1396)$. We excluded 5 cases that had only an Image Guided Radiation Therapy (IGRT) code due to possible cross-referencing with pure diagnostic, non-therapeutic imaging. The final cohort included 39,619 patients.

\section{Measures}

Our primary outcome, palliative radiotherapy, was identified in patient claims files using Healthcare Common Procedure Coding System (HCPCS) codes (Additional file 1). Radiation therapy was considered in the last 6 months of life and separately in the last 14 days of life. Palliative radiotherapy was defined by a combination of patient cohort (all patients with stage 4 cancer would have been treated, by definition, with palliative intent) and cause of death (earlier-stage patients who died due to cancer).

Independent variables included the following clinical and sociodemographic factors: sex, race/ethnicity, age at diagnosis, marital status (unmarried, including: single, separated, divorced, or widowed; compared with married, including common law), Charlson index of comorbidity (calculated for two years prior to the last six months of life) [20]. We also included Census Tract level variables at the time of initial cancer diagnosis including: Region, Urban/Rural setting (divided into "Urban," "Metro Urban," and "Rural"), median household income (above/ below median income of $\$ 43,000$ ), and education (percent of persons over age 25 with a high school education only above/below median of $28 \%$ ). Clinical variables included year of diagnosis, cancer type, stage at diagnosis $(0-3,4)$, cause of death, time from diagnosis until death and the use of prior radiation (radiation therapy received prior to the last 6 months of life). The use of surgery, chemotherapy, 

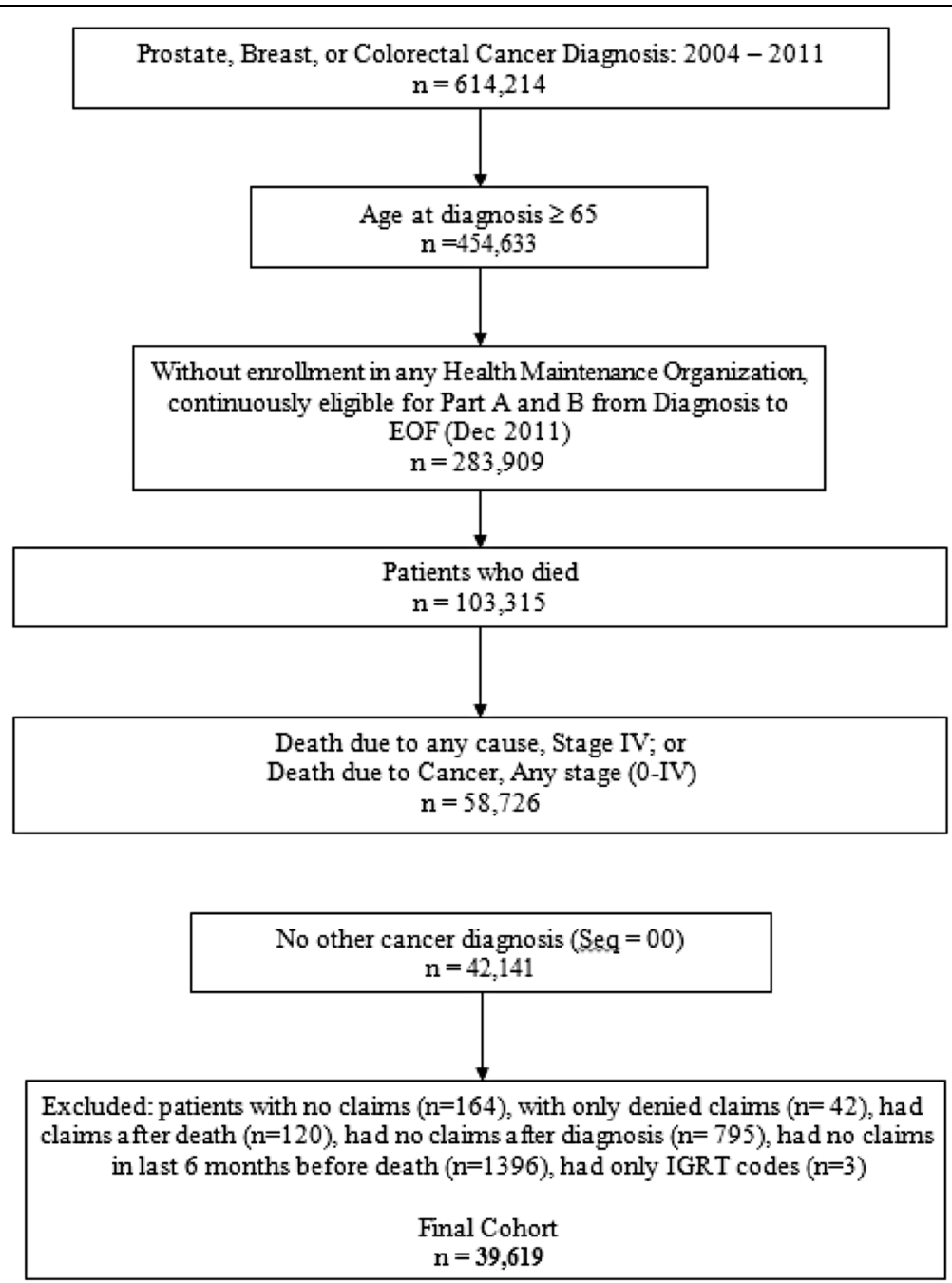

Figure 1 Cohort development from SEER-Medicare linked database.

and radiologic examinations in the last 6 months were identified using a comprehensive list of HCPCS/Current Procedure Terminology (CPT) codes in the last 6 months of life (Additional file 1). Total inpatient days, emergency department visits, and physician visits were also calculated for the last six months of life.

Using a method developed by other investigators, patients were also designated as having had radiation in a freestanding facility versus a hospital-based or other type of facility by comparing the outpatient and carrier claims files [21].

\section{Statistical analyses}

We first calculated summary statistics regarding the distributions of total inpatient days, emergency department visits, radiologic exams and physician visits to assess differences in utilization of healthcare between patients with and without palliative radiation use in the last 6 months of life. We then calculated percentages of palliative radiation use. Third, we performed chi-square tests for categorical variables and t-tests for continuous variable to compare the distribution of demographic and clinical factors between patients who did or did not get radiation in the last 6 months and 14 days of their lives. Fourth, we created multiple logistic regression models to identify those factors independently associated with palliative radiation use (as the binary dependent variable), adjusting for all other patients' sociodemographics and clinical factors. Final results are presented as odds ratios with $95 \%$ confidence interval. All p-values were twosided, and a p-value smaller than 0.01 was considered statistically significant. All analyses were conducted using the SAS 9.2 software (Cary, NC).

\section{Results}

Receipt of radiation in the last six months of life

Among the 39,619 patients included in this cohort, 50\% received RT in the last six months of life. Bivariable 
analysis of RT use according to multiple sociodemographic, clinical, and health systems characteristics is presented in Table 1. Of patients aged $65-69,63 \%$ received RT; rates of RT decreased through the oldest cohort, age $>85$, with 38\% receiving RT (trend from 65 to over $85, \mathrm{p}<0.0001)$. RT was used less commonly in nonHispanic whites, as compared with all other racial/ethnic groups ( $\mathrm{p}<0.0001$ ). Between 2004 and 2009, an increasing percentage of patients were treated with $\mathrm{RT}$ each year $(\mathrm{p}<0.0001)$. When separated by stage, $54 \%$ of those with stage 0-3 cancer at diagnosis received RT in the last 6 months of life; $51 \%$ of those with stage 4 cancer received $\mathrm{RT}$ in the last 6 months of life ( $<<0.0001)$. When evaluating the time alive from diagnosis until death, $55 \%$ of patients alive for 6 months or fewer received RT, while those alive for longer periods of time had rates of RT ranging from $46-48 \%$.

Fifty-two percent of patients with radiation prior to the last six months also had RT in the last 6 months of life, while only $46 \%$ of those with no prior history of RT received it at the end of life $(\mathrm{p}<0.0001)$. Thirty-five percent of patients had surgery in the last six months of life, with proportionally more patients undergoing RT who also had surgery during the last 6 months of life $(\mathrm{p}<0.0001)$.

Patients who received RT in the six months of life ( $\mathrm{n}=19,856)$ were compared with those not treated with RT during this time period $(n=19,763)$. There were significant differences in subjects' utilization of additional health care resources, presented in Table 2. Mean total inpatient days in the last six months of life did not differ between the two groups. Emergency Department visits, radiologic exams, and physician visits were all higher among patients receiving RT at the end of life $(p<0.0001$ for all three comparisons).

Our study included patients initially diagnosed with cancer stages $0-3$ who died due to cancer and those initially diagnosed with stage 4 cancer who died of any cause. We initially explored these two groups using two separate multivariate logistic models with respect to the multiple factors related to the receipt of palliative RT at the end of life. We found that the association between sociodemographic and clinical factors and receipt of palliative RT was similar across the two groups (Additional files 2 and 3). Therefore, for subsequent analysis, we combined the groups and included stage at diagnosis as a covariate.

Multivariate analysis of the entire study cohort is presented in Table 3. Non-white patients were more likely to receive RT than non-Hispanic white patients (OR 1.18, CI 1.12-1.25). The odds of receiving RT decreased with increasing age, with patients over age 85 least likely to receive RT (OR 0.41, CI 0.38-0.44). RT was used more often in patients also receiving chemotherapy in the last
6 months of life (OR 2.78, CI 2.63-2.93) or surgery in the last 6 months of life (OR 1.17, CI 1.11-1.23). Patients with stage 4 were less likely to undergo RT than those initially diagnosed with stage $0-3$ (OR 0.70 , CI 0.66-0.73).

\section{Receipt of radiation in the last fourteen days of life}

5,723 patients $(14 \%)$ received RT within the last fourteen days of life; sociodemographic and clinical factors related to their treatment are also presented in Table 1. Fourteen percent of non-Hispanic white patients received RT during this time period, while $17 \%$ of all other racial/ethnic groups received RT $(\mathrm{p}<0.0001)$. Of patients age $65-69,20 \%$ received RT in the last fourteen days of life; rates of RT decreased through the oldest cohort, age $>85$, with $11 \%$ of patients in that age group receiving RT $(\mathrm{p}<0.0001)$. Eighteen percent of patients alive for 6 months or fewer from diagnosis until death received RT, compared to $12 \%$ of all other groups $(\mathrm{p}<0.0001)$. Among patients receiving chemotherapy in the last 14 days of life, $36 \%$ of these patients also received RT, while $9-15 \%$ of patients not receiving chemotherapy in the last 14 days received $\mathrm{RT}$ during this time period $(\mathrm{p}<0.0001)$.

The results of multivariate analysis of radiation therapy use in the last fourteen days of life were overall similar to the findings for RT given during the last six months of life and are presented in Additional file 4. However, a few notable differences include that patients with prostate cancer approached the rate of radiation therapy use of breast cancer patients in the last fourteen days of life. Additionally, radiation therapy was less associated with other hightreatment-intensity interventions in the last fourteen days of life than in the last six months of life.

\section{Discussion}

This study is the first to examine the use of RT at the end of life for major solid cancers with a relatively long natural history, including analysis of outcomes both for patients with metastatic cancer and those who died due to cancer after an initial diagnosis of non-metastatic disease. The goal of this study was to examine a generalizable group of patients who would be most likely to receive palliative, non-curative RT, regardless of stage at initial diagnosis. In our cohort of palliative patients, half of all patients received at least one course of RT within 6 months of death, and even in the last 14 days of life.

Radiation use decreased with increasing age and was less common among non-Hispanic white patients, after controlling for all other characteristics. These trends were consistent when looking both at the last six months and last fourteen days of life, and are similar to results reported in other studies of palliative radiotherapy [15-18], palliative chemotherapy [22], and end-of-life care in general $[23,24]$. One recent study examined the use of radiation therapy in the last 30 days of life among 
Table 1 Radiation therapy at the end of life: within six months or fourteen days of death

\begin{tabular}{|c|c|c|c|c|c|}
\hline & \multirow{2}{*}{$\begin{array}{l}\text { All } \\
n\end{array}$} & \multicolumn{2}{|l|}{6 Months } & \multicolumn{2}{|l|}{14 Days } \\
\hline & & n (\%) & $p$ value & n (\%) & $p$ value \\
\hline Total & 39,619 & $19856(50)$ & & $5723(14)$ & \\
\hline Sex & 20,722 & & 0.0183 & & $<.0001$ \\
\hline Female & & $10268(50)$ & & $2834(14)$ & \\
\hline Male & 18,897 & $9588(51)$ & & $2889(15)$ & \\
\hline Race/ethnicity & 30,904 & & $<.0001$ & & $<.0001$ \\
\hline Non-Hispanic White & & $15106(49)$ & & 4279 (14) & \\
\hline Non-Hispanic Black & 4,791 & $2606(54)$ & & $763(16)$ & \\
\hline Hispanic & 2,250 & $1268(56)$ & & $399(18)$ & \\
\hline Other & 1,674 & $876(52)$ & & $282(17)$ & \\
\hline Race/ethnicity & 30,904 & & $<.0001$ & & $<.0001$ \\
\hline Non-Hispanic White & & $15106(49)$ & & 4279 (14) & \\
\hline All others & 8,715 & $4750(55)$ & & $1444(17)$ & \\
\hline Age at diagnosis & 5,308 & & $<.0001$ & & $<.0001$ \\
\hline Age $65-69$ & & $3328(63)$ & & $1071(20)$ & \\
\hline Age $70-74$ & 6,154 & 3633 (59) & & $1065(17)$ & \\
\hline Age $75-79$ & 7,367 & $4027(55)$ & & $1160(16)$ & \\
\hline Age $80-84$ & 8,599 & $4206(49)$ & & $1138(13)$ & \\
\hline $85+$ & 12,191 & $4662(38)$ & & $1289(11)$ & \\
\hline Charlson index & 17,075 & & 0.2403 & & 0.0835 \\
\hline 0 & & $8628(51)$ & & $2558(15)$ & \\
\hline 1 & 10,203 & $5048(49)$ & & $1436(14)$ & \\
\hline 2 or more & 12,341 & $6180(50)$ & & $1729(14)$ & \\
\hline Census region & 17,246 & & $<.0001$ & & $<.0001$ \\
\hline West & & $8768(51)$ & & $2597(15)$ & \\
\hline South & 15,733 & $7666(49)$ & & $2129(14)$ & \\
\hline North & 4,082 & $2111(52)$ & & $633(16)$ & \\
\hline East & 2,558 & $1311(51)$ & & $364(14)$ & \\
\hline Urban/rural & 20,695 & & $<.0001$ & & $<.0001$ \\
\hline Urban & & $10908(53)$ & & $3312(16)$ & \\
\hline Metro Urban & 11,506 & $5666(49)$ & & 1575 (14) & \\
\hline Rural & 7,410 & $3279(44)$ & & $835(11)$ & \\
\hline Missing/unknown & 8 & $3(38)$ & & $1(13)$ & \\
\hline Median income & 19,689 & & 0.0053 & & 0.0107 \\
\hline Above median ( $43 \mathrm{~K}$ ) & & $10017(51)$ & & $2925(15)$ & \\
\hline Below median (43 K) & 19,686 & 9739 (49) & & $2772(14)$ & \\
\hline Missing/ unknown & 244 & $100(41)$ & & $26(11)$ & \\
\hline High school only & 19,693 & & $<.0001$ & & $<.0001$ \\
\hline Above median (28\%) & & $9664(49)$ & & $2707(14)$ & \\
\hline Below median (28\%) & 19,694 & $10096(51)$ & & $2992(15)$ & \\
\hline Missing/unknown & 232 & $96(41)$ & & $24(10)$ & \\
\hline
\end{tabular}


Table 1 Radiation therapy at the end of life: within six months or fourteen days of death (Continued)

\begin{tabular}{|c|c|c|c|c|c|}
\hline Marital status & 21,554 & & $<.0001$ & & $<.0001$ \\
\hline Unmarried & & $10199(47)$ & & $2796(13)$ & \\
\hline Married & 15,354 & $8357(54)$ & & $2553(17)$ & \\
\hline Missing/unknown & 2,711 & $1300(48)$ & & $374(14)$ & \\
\hline Year of diagnosis & 8,903 & & $<.0001$ & & $<.0001$ \\
\hline 2004 & & $4257(48)$ & & $1207(14)$ & \\
\hline 2005 & 8,092 & $4009(50)$ & & $1156(14)$ & \\
\hline 2006 & 7,312 & 3611 (49) & & $996(14)$ & \\
\hline 2007 & 6,239 & $3258(52)$ & & $971(16)$ & \\
\hline 2008 & 5,194 & $2674(51)$ & & 790 (15) & \\
\hline 2009 & 3,879 & $2047(53)$ & & $603(16)$ & \\
\hline Cancer type & 8,629 & & $<.0001$ & & $<.0001$ \\
\hline Breast & & $4641(54)$ & & $1292(15)$ & \\
\hline Colorectal & 21,469 & $10318(48)$ & & 3039 (14) & \\
\hline Prostate & 9,521 & $4897(51)$ & & $1392(15)$ & \\
\hline Stage & 11,115 & & $<.0001$ & & $<.0001$ \\
\hline $0-3$ & & $5907(53)$ & & $1634(15)$ & \\
\hline 4 & 28,504 & $13949(49)$ & $<.0001$ & 4089 (14) & $<.0001$ \\
\hline Cause of death & 30,293 & $15740(52)$ & & $4508(15)$ & \\
\hline \multicolumn{6}{|l|}{ Cancer } \\
\hline Non Cancer & 9,326 & $4116(44)$ & & $1215(13)$ & \\
\hline Time from diagnosis to death & 17,006 & & $<.0001$ & & $<.0001$ \\
\hline 0 days to 6 months & & $9323(55)$ & & 3089 (18) & \\
\hline 6 months to 1 year & 6,065 & $2910(48)$ & & $719(12)$ & \\
\hline $1-3$ years & 12,160 & $5623(46)$ & & $1407(12)$ & \\
\hline More than 3 years & 4,388 & $2000(46)$ & & $508(12)$ & \\
\hline Prior radiation & 13,303 & & $<.0001$ & & $<.0001$ \\
\hline No & & $6157(46)$ & & $2036(15)$ & \\
\hline Yes & 26,316 & $13699(52)$ & & $3687(14)$ & \\
\hline Radiation Facility & 19,763 & & & & \\
\hline No radiation & & $0(0)$ & & $0(0)$ & \\
\hline Hospital-based or Other & 14,442 & $14442(100)$ & & $4330(30)$ & \\
\hline Freestanding & 5,414 & $5414(100)$ & & $1393(26)$ & \\
\hline Surgery (last 6 months of life) & 25,873 & & $<.0001$ & & $<.0001$ \\
\hline No & & $12681(49)$ & & $3616(14)$ & \\
\hline Yes & 13,746 & $7175(52)$ & & $2107(15)$ & \\
\hline Chemotherapy & 1,585 & & $<.0001$ & & $<.0001$ \\
\hline Last 14 days of life & & $1169(74)$ & & $577(36)$ & \\
\hline Last 6 months of life, but not last 14 days & 10,999 & $7076(64)$ & & $1655(15)$ & \\
\hline None in last 6 months before death & 4,203 & $1694(40)$ & & $396(9)$ & \\
\hline Never & 22,832 & $9917(43)$ & & 3095 (14) & \\
\hline
\end{tabular}

patients who died due to cancer and found significantly lower rates of radiation therapy use [16]. Our study demonstrated higher rates of utilization both due to the larger time window examined as well as the inclusion of patients dying from causes other than cancer. These differences in treatment practice according to age and racial/ethnic group cannot be attributed to relative life expectancy or comorbidity, and thus might represent unmeasured 
Table 2 Health care resource utilization in the last six months of life

\begin{tabular}{|c|c|c|c|c|}
\hline & All & No $\mathrm{RT}^{1}$ & Yes RT & $p$ value \\
\hline Total inpatient days & $25(79)$ & $22(82)$ & $27(71)$ & 0.38 \\
\hline \multicolumn{5}{|c|}{ Median (standard deviation (SD)) } \\
\hline $\begin{array}{l}\text { Total emergency } \\
\text { department visits }\end{array}$ & $2(3)$ & $1(3)$ & $2(3)$ & $<.0001$ \\
\hline \multicolumn{5}{|l|}{ Median (SD) } \\
\hline Total radiologic exams & $10(11)$ & $6(7)$ & $14(11)$ & $<.0001$ \\
\hline \multicolumn{5}{|l|}{ Median } \\
\hline Total physician visits & $20(21)$ & $13(15)$ & $27(23)$ & $<.0001$ \\
\hline Median & & & & \\
\hline
\end{tabular}

variables, such as patient or family preference or cultural beliefs. It is possible that older patients, as well as those who have been alive with cancer for a longer period of time, have lower RT utilization as part of a broader pattern of low resource utilization at the end of life.

RT use was also associated with higher utilization of health care resources, including chemotherapy use, surgery, physician visits, emergency department visits, and number of radiologic exams. Increased health care utilization at end of life has been shown to be an expensive, nuanced issue $[1,2]$. These findings have implications regarding the quality and appropriateness of care at the end of life. Welltimed palliative radiotherapy can alleviate cancerrelated symptoms and thereby improve patients' quality of life in a cost-effective manner. It is possible that this "window" of appropriate care includes the last 6 months of life, as examined in this study. It is impossible in this study to discern whether RT use prevented further interventions (i.e. additional surgery, chemotherapy, or hospitalizations), was part of a general pattern of "highutilization" of health care resources at the end of life among selected patients, or affected patients' quality of life. However, our data suggest that end of life RT conforms to similar utilization patterns as other cancer treatments, such as chemotherapy, either when comparing longer and shorter time windows (6 months vs. 14 days) or comparing patients diagnosed with metastatic vs. nonmetastatic cancer. Cancer-directed treatment within the last 2 weeks of life may not always be appropriate. ASCO's Quality Oncology Practice Initiative (QOPI) measures, for example, note that chemotherapy in the last fourteen days of life is considered low quality, possible detrimental endof life care $[12,13]$.

Clinically, tailoring end-of-life care remains a challenge related to anticipating date of death; measuring quality of life for both patients and caregivers; and communicating clear expectations among caregivers, patients, and patient families. Given the limited guidance about palliative RT for this patient group nearing end of
Table 3 Multivariate model $^{1}$ : radiation in last six months of life ${ }^{2}$

\begin{tabular}{lllll}
\hline & OR & $\mathbf{9 5 \%} \mathrm{Cl}$ & P value \\
\hline $\begin{array}{l}\text { Race/ethnicity } \\
\quad \text { Non-Hispanic White }\end{array}$ & & & & \\
$\quad$ All Others & 1.18 & 1.12 & 1.25 & $<.0001$ \\
Age at diagnosis & & & & \\
$\quad$ Age $65-69$ & & & & \\
Age $70-74$ & 0.86 & 0.79 & 0.93 & 0.0002 \\
Age $75-79$ & 0.74 & 0.68 & 0.80 & $<.0001$ \\
Age $80-84$ & 0.61 & 0.57 & 0.66 & $<.0001$ \\
85+ & 0.41 & 0.38 & 0.44 & $<.0001$ \\
Charlson index & & & & \\
0 & & & & \\
1 & 1.01 & 0.96 & 1.07 & 0.6427 \\
2 or more & 1.07 & 1.01 & 1.13 & 0.0144
\end{tabular}

\section{Marital status}

Unmarried

Married

$\begin{array}{llll}1.15 & 1.10 & 1.20 & <.0001\end{array}$

Cancer type

Breast

Colorectal

Prostate

$\begin{array}{llll}0.65 & 0.62 & 0.69 & <.0001\end{array}$

$\begin{array}{llll}0.82 & 0.76 & 0.88 & <.0001\end{array}$

Prior radiation

No

Yes

Surgery (last 6 months of life)

No

Yes

$\begin{array}{llll}1.17 & 1.11 & 1.23 & <.0001\end{array}$

Chemotherapy (last 6 months of life)

No

Yes

$2.78 \quad 2.63 \quad 2.93 \quad<.0001$

Stage at diagnosis

$0-3$

4

$\begin{array}{llll}0.70 & 0.66 & 0.73 & <.0001\end{array}$

${ }^{1}$ Referent group is the first line in each category, unless otherwise indicated. ${ }^{2}$ Additional factors for which we controlled in the multivariate model included census region, urban/rural designation, education, and time alive from diagnosis until death.

life, future research is needed to explore and define appropriateness and value in end-of-life RT as part of a comprehensive end-of-life plan for patients with cancer.

The central limitation to our study relates to the definition of "palliative" radiation therapy using administrative claims data. Although the cohort was designed to include patients undergoing palliative radiotherapy, it is possible that some patients were treated with curative intent within 6 months of death. Since our findings persisted 
with sub-group analyses, including treatment within 14 days before death, and the magnitude of differences were similar between metastatic and non-metastatic patients, we are confident that this cohort was treated with palliative intent. Similarly, no information was available regarding physician decision-making, patients' presenting complaints, or patient preference in this data set. Additionally, patients with breast, prostate, or colorectal cancer frequently have extended survival even when they are deemed to have incurable disease, making even a large window of time (i.e. 6 months) before death reasonable for palliative care analysis. Hospice data was not included in this analysis, so our findings are only applicable to patients who were not enrolled in hospice in the intervals studied. The SEER-Medicare data set itself has limitations due to its use of claims-based data only for a population of older patients within a system that is entirely fee-forservice. Additionally, due to the nature of the SEERMedicare data, we were unable to extract data regarding radiation dose nor determine the start and stop times of individual courses of RT.

\section{Conclusions}

Among subjects with cancer diagnoses where a prolonged lifespan is common, even in the setting of incurable malignancies, the use of RT in the final six months of life was common. The use of RT appeared was associated with other cancer-directed treatments, including chemotherapy, at the end of life. Recently published guidelines highlight the importance of tracking the use of high-cost, high-treatment-intensity approaches at the end of life and carefully tailoring treatment plans to maximize quality of life and minimize treatment burden that does not provide value to quality of life $[14,25]$. More research is needed to refine clinical quality objectives for end of life cancer care, to optimize the role of RT as a palliative tool at the end of life, and to elucidate the psychosocial and unmeasured clinical factors influencing end-of-life care.

\section{Additional files}

\section{Additional file 1: Radiotherapy, surgical, chemotherapy, and radiology codes. \\ Additional file 2: Radiation Therapy at the End of Life, by Stage at Diagnosis. \\ Additional file 3: Multivariate Model ${ }^{1}$ : Radiation in the Last 6 Months of Life, by Stage. \\ Additional file 4: Multivariate Model $^{1}$ : Radiation in the Last Fourteen Days of Life.}

\section{Competing interests}

The authors declare that they have no competing interests. Potential conflicts of interest: Employment or Leadership Position; Consultant or Advisory Role; Stock Ownership; Honoraria; Research Funding; Expert Testimony; Other Remuneration.

\section{Authors' contributions}

Concept and design: MSK, RQJ, AS, ALP. Financial support: ALP, AS. Administrative support: ALP, TL. Provision of study materials or patients: ALP AS. Collection and assembly of data: MSK, REJ, TL, HTT. Data analysis and interpretation: All authors read and approved the final manuscript.

\section{Research support}

This project is supported by Award Number P30CA051008 from the National Cancer Institute. The content is solely the responsibility of the authors and does not necessarily represent the official views of the National Cancer Institute or the National Institutes of Health.

\section{Author details}

1Huron River Radiation Oncology, 5301 E Huron River Dr Ann Arbor, Michigan 48106, USA. 'Lombardi Comprehensive Cancer Center, Georgetown University Medical Center, 3300 Whitehaven St, NW Suite 4000, Washington, DC 20007, USA.

Received: 27 June 2014 Accepted: 15 December 2014 Published online: 13 January 2015

\section{References}

1. Lewin SN, Buttin BM, Powell MA, Gibb RK, Rader JS, Mutch DG, et al. Resource utilization for ovarian cancer patients at the end of life: how much is too much? Gynecol Oncol. 2005;99:261-6.

2. Pyenson B, Connor S, Fitch K, Kinzbrunner B. Medicare cost in matched hospice and non-hospice cohorts. J Pain Symptom Manage. 2004;28:200-10.

3. Greenberg PA, Hortobagyi GN, Smith TL, Ziegler LD, Frye DK, Buzdar AU. Long-term follow-up of patients with complete remission following combination chemotherapy for metastatic breast cancer. J Clin Oncol. 1996;14:2197-205.

4. Yossepowitch O, Bianco Jr FJ, Eggener SE, Eastham JA, Scher HI, Scardino PT. The natural history of noncastrate metastatic prostate cancer after radical prostatectomy. Eur Urol. 2007;51:940-7.

5. Skeel RT. Quality of life dimensions that are most important to cancer patients. Oncology (Williston Park). 1993;7:55-61.

6. World Health Organization. National Cancer Control Programmes: Policies and managerial guidelines. 2nd ed. Geneva, Switzerland: World Health Organization; 2002

7. Bae SH, Park W, Choi DH, Nam H, Kang WK, Park YS, et al. Palliative radiotherapy in patients with a symptomatic pelvic mass of metastatic colorectal cancer. Radiat Oncol. 2011;6:52.

8. Cross CK, Berman S, Buswell L, Johnson B, Baldini EH. Prospective study of palliative hypofractionated radiotherapy ( $8.5 \mathrm{~Gy} \times 2$ ) for patients with symptomatic non-small-cell lung cancer. Int J Radiat Oncol Biol Phys. 2004;58:1098-105.

9. Konski A. Radiotherapy is a cost-effective palliative treatment for patients with bone metastasis from prostate cancer. Int J Radiat Oncol Biol Phys. 2004;60:1373-8.

10. Howell DD, James JL, Hartsell WF, Suntharalingam M, Machtay M, Suh JH, et al. Single-fraction radiotherapy versus multifraction radiotherapy for palliation of painful vertebral bone metastases-equivalent efficacy, less toxicity, more convenient: a subset analysis of Radiation Therapy Oncology Group trial 97-14. Cancer. 2013;119:888-96.

11. Zeng L, Chow E, Bedard G, Zhang L, Fairchild A, Vassiliou V, et al. Quality of life after palliative radiation therapy for patients with painful bone metastases: results of an international study validating the EORTC QLQBM22. Int J Radiat Oncol Biol Phys. 2012;84:e337-42.

12. American Society of Clinical Oncology. American Society of Clinical Oncology $\left(\mathrm{ASCO}^{\circledast}\right)$ Quality Oncology Practice Initiative (QOPI $\left.{ }^{\circledR}\right)$. 2014. http:// qopi.asco.org/documents/QOPIQCDR2014.pdf.

13. Schnipper LE, Smith TJ, Raghavan D, Blayney DW, Ganz PA, Mulvey TM, et al. American Society of Clinical Oncology identifies five key opportunities to improve care and reduce costs: the top five list for oncology. J Clin Oncol. 2012;30:1715-24.

14. Lutz S, Berk L, Chang E, Chow E, Hahn C, Hoskin P, et al. Palliative radiotherapy for bone metastases: an ASTRO evidence-based guideline. Int J Radiat Oncol Biol Phys. 2011;79:965-76.

15. Chen AB, Cronin A, Weeks JC, Chrischilles EA, Malin J, Hayman JA, et al. Palliative radiation therapy practice in patients with metastatic non-small- 
cell lung cancer: a Cancer Care Outcomes Research and Surveillance Consortium (CanCORS) Study. J Clin Oncol. 2013;31:558-64.

16. Guadagnolo BA, Liao KP, Elting L, Giordano S, Buchholz TA, Shih YC. Use of radiation therapy in the last 30 days of life among a large population-based cohort of elderly patients in the United States. J Clin Oncol. 2013;31:80-7.

17. Hayman JA, Abrahamse PH, Lakhani I, Earle CC, Katz SJ. Use of palliative radiotherapy among patients with metastatic non-small-cell lung cancer. Int J Radiat Oncol Biol Phys. 2007;69:1001-7.

18. Murphy JD, Nelson LM, Chang DT, Mell LK, Le QT. Patterns of care in palliative radiotherapy: a population-based study. J Oncol Pract. 2013;9:e220-7.

19. National Cancer Institute. Surveillance, Epidemiology, and End Results Program. SEER Website http://www.seer.cancer.gov/.

20. Charlson ME, Pompei P, Ales KL, Mackenzie CR. A new method of classifying prognostic comorbidity in longitudinal studies: development and validation. J Chronic Dis. 1987;40:373-83.

21. Smith BD, Pan IW, Shih YC, Smith GL, Harris JR, Punglia R, et al. Adoption of intensity-modulated radiation therapy for breast cancer in the United States. J Natl Cancer Inst. 2011;103:798-809.

22. Kao S, Shafiq J, Vardy J, Adams D. Use of chemotherapy at end of life in oncology patients. Ann Oncol. 2009;20:1555-9.

23. Parr JD, Zhang B, Nilsson ME, Wright A, Balboni T, Duthie E, et al. The influence of age on the likelihood of receiving end-of-life care consistent with patient treatment preferences. J Palliat Med. 2010;13:719-26.

24. Shugarman LR, Bird CE, Schuster CR, Lynn J. Age and gender differences in medicare expenditures and service utilization at the end of life for lung cancer decedents. Womens Health Issues. 2008;18:199-209.

25. Tsao MN, Rades D, Wirth A, Lo SS, Danielson BL, Gaspar LE, et al. Radiotherapeutic and surgical management for newly diagnosed brain metastasis(es): An American Society for Radiation Oncology evidence-based guideline. Pract Radiat Oncol. 2012;2:210-25.

\section{Submit your next manuscript to BioMed Central and take full advantage of:}

- Convenient online submission

- Thorough peer review

- No space constraints or color figure charges

- Immediate publication on acceptance

- Inclusion in PubMed, CAS, Scopus and Google Scholar

- Research which is freely available for redistribution 